\title{
MODIFIKASI BUBU (TRAP) BERCELAH PELOLOSAN DALAM UPAYA PENANGKAPAN KEPITING BAKAU (Scylla serrata) RAMAH LINGKUNGAN
}

\author{
Aristi Dian Purnama Fitri, Faik Kurohman, Bogi Budi Jayanto, Trisnani Dwi Hapsari, Iqbal A. Husni dan Kukuh E. Prihantoko \\ Departemen Perikanan Tangkap \\ Fakultas Perikanan dan Ilmu Kelautan, Universitas Diponegoro \\ Jl. Prof. Soedarto, SH, Tembalang, Semarang, Jawa Tengah - 50275, Telp/fax. +6224 747698 \\ Email: aristidian.undip@gmail.com
}

Diserahkan tanggal 9 maret 2017 , Diterima tanggal 31 Maret 2017

\begin{abstract}
ABSTRAK
Peraturan Menteri Kelautan Perikanan RI nomor 1 Tahun 2015 menetapkan ukuran lebar karapas untuk Kepiting Bakau (Scylla serrata) layak tangkap minimal $15 \mathrm{~cm}$. Konstruksi trap yang digunakan untuk menangkap Scylla serrata di perairan Rembang memberikan peluang tertangkapnya stadia juvenille $(<10 \mathrm{~cm} \mathrm{CW})$. Trap dengan inovasi celah pelolosan diasumsikan dapat meloloskan Scylla serrata stadia juvenille. Desain celah pelolosan berbentuk segi empat terletak sepanjang bagian sisi bawah trap dengan ukuran tinggi $3 \mathrm{~cm}$, memberikan hasil tangkapan Scylla serrata yang terkecil berukuran lebar karapas rata-rata $8,3 \mathrm{~cm}$ dibandingkan tanpa celah pelolosan dengan ukuran terkecil lebar karapas rata-rata 5,3 cm. Tertangkapnya Scylla serrata dengan desain trap bercelah pelolosan $<10 \mathrm{~cm} \mathrm{CW}$ (stadia juvenille) mengindikasikan bahwa populasi biota tersebut di perairan Rembang berukuran kecil pada saat dilakukannya penelitian pada bulan April sampai dengan Juni 2016.
\end{abstract}

Kata kunci: Bubu, Celah pelolosan, Kepiting bakau (Scylla serrata), Perairan Rembang

\section{ABSTRACT}

Regulation of the Minister of Marine and Fisheries of the Republic of Indonesia No. 1 / 2015 set the legal size of Mud crab (Scylla serrata) at least $15 \mathrm{~cm}$ carapace width. The trap construction used to capture Scylla serrata in Rembang waters provides an opportunity for capturing juvenile stadia $(<10 \mathrm{~cm}$ carapace width $/ \mathrm{CW})$. The innovation of trap with the escape gap is assumed to pass Scylla serrata juvenille stadia. The design escape gap of a rectangular is located along the underside of the trap with a height of $3 \mathrm{~cm}$, giving the smallest Scylla serrata catches the width of an average carapace by $8.3 \mathrm{~cm}$ compared with no escape passes with the smallest size of the average carapace width of $5.3 \mathrm{~cm}$. The capture of Scylla serrata with the trap design of a $10 \mathrm{~cm} \mathrm{CW}$ (juvenile stadia) trap indicates that the biota population in Rembang waters is small in the case of a study in April to June 2016.

Keywords: Trap, Escape gap, Trap, Mud crab (Scylla serrata), Rembang waters

\section{PENDAHULUAN}

Kabupaten Rembang terletak di Pantai Utara provinsi Jawa Tengah, merupakan kawasan pesisir pantai seluas 355,95 $\mathrm{km}^{2}$ dengan potensi sumberdaya ikan mencapai $34.617 .671 \mathrm{~kg}$. (Kurniadi, 2010 dan DKP, 2010). Disisi lain, kabupaten Rembang memiliki kawasan ekosistem hutan mangrove yang cukup baik dan lebat, hal tersebut diikuti dengan terjaganya kawasan ekosistem pesisir beserta biotanya, sepertinya kepiting bakau (Amrulloh, 2011). Konservasi sumberdaya laut terutama di perairan zona I penangkapan (termasuk daerah pesisir pantai) sangat penting, mengingat keanekaragaman biota yang ada sangat besar sehingga diperlukan suatu alat tangkap yang ramah lingkungan. Freindly fishing gears sangat diperlukan untuk menjaga kondisi sumberdaya tetap lestari (tidak over fishing) (Arimoto 2001). Hal tersebut dipertegas pula dengan aturan yang dikeluarkan oleh SEAFDEC bahwa suatu alat penangkapan yang dioperasikan harus selektif, yang didesain untuk dapat meloloskan hasil tangkapan dengan ukuran yang tidak layak tangkap maupun yang bukan target penangkapan (Sondita 2005).

Berdasarkan Peraturan Menteri Kelautan Perikanan RI nomor 2/PERMEN -KP/2015 dan nomor 71/PERMEN$\mathrm{KP} / 2016$ menetapkan bahwa bubu termasuk alat tangkap penjebak yang legal dan diizinkan dioperasikan diseluruh perairan Indonesia. Bubu (trap) merupakan alat tangkap yang sifatnya pasif dan menetap di lokasi daerah penangkapan ikan. Sifat alat bubu tersebut memberikan peluang biota seperti kepiting bakau dan rajungan dengan segala ukuran baik yang undersize hingga legal size dapat tertangkap (Fitri et al., 2017; Nadhifa, 2014 dan Asriyanto dkk, 2014).

Peraturan Menteri Kelautan Perikanan RI nomor: 1/PERMEN-KP/2015 pasal 3 menegaskan bahwa ukuran minimal lobster, kepitingan dan rajungan yang diizinkan untuk

\footnotetext{
C Copyright by Saintek Perikanan (Indonesian Journal of Fisheries Science and Technology), ISSN : 1858-4748
} 
ditangkap berturut turut berukuran panjang karapas $>8 \mathrm{~cm},>$ $15 \mathrm{~cm}$ dan $>10 \mathrm{~cm}$. Hal tersebut mengindikasikan bahwa ukuran ketiga biota layang tangkap yang diizinkan adalah telah pernah melakukan pemijahan minimal dalam 1 (satu) kali produksi. Septiyaningsih dkk (2013) menjelaskan bahwa berat Scylla sp yang telah matang telur adalah $250 \mathrm{gr}$ atau sebanding dengan ukuran panjang karapas $15 \mathrm{~cm}(150 \mathrm{~mm})$. Mengingat ketika suatu kawasan pesisir terjadi eksploitasi sumberdaya, tetap memperhatikan sustainable fisheries (keberlanjutan) dan ramah lingkungan. Inovasi konstruksi bubu lipat dengan celah pelolosan diharapkan memberikan peluang kepiting bakau (Scylla serrta) under size (lebar karapas $<10 \mathrm{~cm}$ ) serta ukuran yang dianggap ilegal pemerintah (lebar karapas $<15 \mathrm{~cm}$ ) yang menjadi target tangkapan utama dapat meloloskan diri keluar dari bubu.

Makalah ini mengkaji tentang hasil tangkapan Scylla serrata dengan menggunakan bubu lipat dengan inovasi celah pelolosan, dari sisi jumlah hasil tangkapan, ukuran terkecil dan terbesar lebar karapas (carapcs weight) Scylla serrata yang tertangkap dan efektivitas penangkapan. Manfaat yang diperoleh adalah alat tangkap bubu dengan inovasi celah pelolosan untuk menangkap Scylla serrata yang dapat diaplikasikan pada nelayan penangkapan Scylla serrata sesuai peraturan pemerintah nomor. 1/PERMEN-KP/2015, khususnya di perairan Rembang, Jawa Tengah.

\section{METODE PENELITIAN}

Metode penelitian adalah deskriptif analisis. Pelaksanaan kegiatan di perairan Kaliori, Kabupaten Rembang pada bulan Mei-Oktober 2016 dengan lokasi penelitian sebagai setting bubu adalah perairan habitat Scylla serrata (mangrove dan substrat lumpur berpasir).

Metode pengumpulan data secara observasi dan survei, dan data yang dikumpulkan meliputi jumlah (ekor) dan ukuran lebar karapas hasil tangkapan Scylla serrata dari alat tangkap bubu bercelah pelolosan dengan membandingkannya dengan bubu tanpa celah pelolosan yang digunakan nelayan periaran Kaliori. Setting penangkapan dilakukan sebanyak 4 (empat) kali dengan jumlah bubu yang digunakan masing-masing konstruksi yang berbeda sebanyak 10 buah. Analisis data meliputi efektivitas penangkapan Scylla serrata dari kedua konstruksi bubu (bercelah pelolosan dan tanpa celah pelolosan), dengan rumus :

Efektivitas penangkapan $(\mathrm{Ef})=\frac{H T x \operatorname{atas} y}{\mathrm{HT} x+\mathrm{HT} y}$

HT $\mathrm{x}=$ Hasil Tangkapan (ekor) konstruksi bubu $\mathrm{x}$

HT y = Hasil Tangkapan (ekor) konstruksi bubu y

Desain dan konstruksi bubu bercelah pelolosan dapat dilihat pada Lampiran 1.

\section{HASIL DAN PEMBAHASAN}

Perairan Kaliori, Kabupaten Rembang. Luas wilayah Kaliori yaitu $7.299 \mathrm{H} / \mathrm{m}^{2}$, dengan batas administrasi :

$\begin{array}{lc}\text { Sebelah Utara } & \text { : Laut Jawa } \\ \text { Sebelah Timur } & \text { : Kecamatan Lasem } \\ \text { Sebelah Selatan } & \text { : Kelurahan Magersari }\end{array}$

Sebelah Barat : Desa Tritunggal

Data hasil tangkapan bubu selama pengamatan dengan target tangkapan utama adalah Mud crab (Scylla serrata), di perairan Rembang tersaji pada Gambar 1.

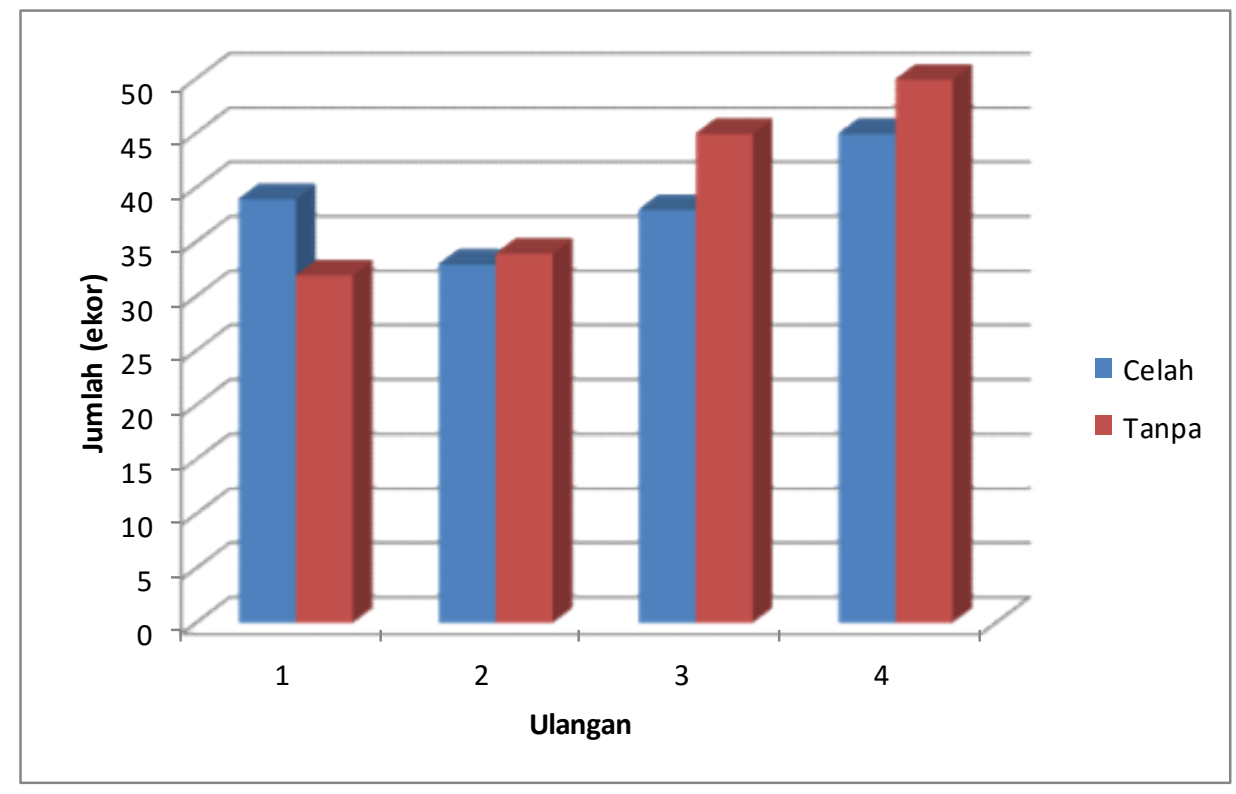

Gambar 1. Jumlah tangkapan Scylla serrata selama penelitian

Gambar 1 menunjukkan bahwa Scylla serrata yang tertangkap selama penelitian antara bubu dengan celah pelolosan dan tanpa celah pelolosan tidak memiliki perbedaan. Hal tersebut mengindikasikan bahwa ukuran Scylla serrata yang terdapat pada habitat tersebut memiliki kecenderungan ukuran lebar karapas kurang dari $12 \mathrm{~cm}(<12 \mathrm{~cm})$. Kondisi tersebut bisa disebabkan karena waktu penelitian berlangsung saat musim peralihan, dimana kondisi tersebut ditandai dengan ukuran Scylla serrata masuk stadia sub adult (Fitri et al., 2017a dan Fitri et al., 2017b).

Fungsi utama dari adanya inovasi celah pelolosan dari alat tangkap bubu dapat dilihat dari Tabel 1. Tabel 1 memberikan informasi tentang fungsi selektivitas bubu 
bercelah untuk dapat meloloskan Scylla serrata stadia juvenile

(lebar karapas kurang dari $12 \mathrm{~cm}$ ).

Tabel 1. Ukuran lebar karapas Scylla serrate hasil tangkapan

\begin{tabular}{cccc}
\hline $\begin{array}{c}\text { Bubu Bercelah } \\
\text { Lebar Karapas Minimal (cm) }\end{array}$ & Jumlah (ekor) & $\begin{array}{c}\text { Bubu Tanpa Celah } \\
\text { Lebar Karapas Minimal (cm) }\end{array}$ & Jumlah (ekor) \\
\hline 7 & 5 & 3 & 9 \\
6,5 & 2 & 3 & 5 \\
5,4 & 10 & 3,4 & 7 \\
5,2 & 6 & 2,5 & 2 \\
5,2 & 2 & 2 & 5 \\
4,4 & 1 & 2,5 & 2 \\
\hline Jumlah & $\mathbf{2 6}$ & Jumlah & $\mathbf{3 0}$
\end{tabular}

Berdasar data Tabel 1 menunjukkan bahwa bubu dengan celah pelolosan mendapatkan Scylla serrata dengan ukuran minimal lebar karapas lebih besar dibandingkan dengan menggunakan bubu tanpa celah pelolosan, dimana lebar karapas Scylla serrata terkecil pada bubu bercelah $4,4 \mathrm{~cm}$ sebanyak 1 ekor sedangkan pada bubu tanpa celah ukuran Scylla serrate lebar karapas terkecil 2,5 cm sebanyak 2 ekor. Hal tersebut mengindikasikan bahwa bubu dengan celah pelolosan mampu menahan Scylla serrata ukuran lebar karapas Scylla serrata terendah $4,4 \mathrm{~cm}$ saja, meskipun ukuran lebar karapas terkecil pada bubu bercelah masih ada yang masuk dalam stadia juvenile.

Apabila dikaji dari tingkat efektivitas penangkapan, konstruksi bubu bercelah pelolosan dan tanpa celah pelolosan memiliki nilai yang tidak jauh berbeda, dimana nilai efektivitas bubu dengan celah pelolosan yaitu 64,5\% dan bubu tanpa celah pelolosan yaitu $66,1 \%$. Kondisi tersebut terjadi karena ukuran Scylla serrata dengan lebar karapas yang hampir sama terdapat pada ekosistem dimana dilakukannya penelitian. Disisi yang lain, faktor tingkah laku Scylla serrata pada stadia juvenille dan sub adult memiliki kecenderungan untuk berkelompok dan mendiami suatu tempat (Fitri, 2013). Apabila ditinjau dari nilai efektivitas penangkapan, nilai efektivitas penangkapan dengan bubu tanpa celah pelolosan lebih besar dibandingkan bubu dengan celah pelolosan. Nilai tersebut disebabkan kemampuan bubu tanpa celah dapat menangkap Scylla serrata dengan semua ukuran baik stadia adult sampai stadia juvenile (lebar karapas terkecil tertangkap 2,5 cm). Dapat dikatakan bahwa penangkapan dengan bubu dengan celah pelolosan penangkapan bukan ditujukan untuk penangkapan dengan jumlah terbanyak (kuantitas) melainkan dari penentuan kualitas hasil tangkapan.

Penangkapan dengan menggunakan bubu bercelah dapat memberikan keuntungan, antara lain bahwa hasil tangkapan masih dalam kondisi hidup saat dilakukannya hauling (Martasuganda, 2012). Selain itu, berdasarkan pengelompokkan alat tangkap berdasarkan metode operasinya, bubu bercelah termasuk alat tangkap yang pasif dan selektif, hal ini didasarkan atas hasil tangkapan bubu bercelah yang dapat diseleksi oleh manusia saat hauling sehingga dapat dipisahkan antara hasil tangkapan yang masih berukuran anakan /juvenile atau yang sudah masuk layak konsumsi. Setting bubu bercelah yang dapat dilakukan sepanjang musim penangkapan, mengindikasikan bahwa bubu bercelah dapat dijadikan alternative alat penangkapan ikan saat musim paceklik penangkapan dilaut.

\section{KESIMPULAN}

Dari hasil kegiatan pengabdian, dapat ditarik kesimpulan sebagai berikut:

1. Bubu dengan celah pelolosan mendapatkan hasil tangkapan lebih sedikit jumlahnya dibandingkan bubu tanpa celah pelolosan

2. Ukuran lebar karapas terkecil Scylla serrata yang tertangkap pada bubu dengan celah pelolosan lebih besar $(4,4 \mathrm{~cm})$ dibandingkan yang tertangkap pada bubu tanpa celah pelolosan $(2,5 \mathrm{~cm})$

3. Efektivitas penangkapan Scylla serrata pada bubu dengan celah pelolosan sebesar $64,5 \%$ dan tanpa celah pelolosan sebesar $66,1 \%$

\section{UCAPAN TERIMA KASIH}

Penulis mengucapkan terima kasih kepada Dikti SIMLITABMAS yang telah membiayai pelaksanaan kegiatan pengabdian IbM dengan SPK No: 008/SP2H/PPM/DRPM/II/2016, Tanggal 17 Februari 2016. Penulis juga mengucapkan terima kasih kepada Sau Saudara Afif Rahman, S.Pi atas bantuannya dalam melakukan pengumpulan data lapangan.

\section{DAFTAR PUSTAKA}

Amrulloh, F. 2011. Pengaruh Perbedaan Bentuk Mulut dan Posisi Setting Alat Tangkap Fyke Net (Hari ami) terhadap Jumlah Hasil Tangkapan Di Perairan Kaliuntu, Pasarbanggi, Rembang. [skripsi]. Tidak Dipublikasikan. Fakultas Perikanan dan Ilmu Kelautan. Universitas Diponegoro.

Departemen Kelautan dan Perikanan. 2010. Profil Potensi Kelautan dan Perikanan Kabupaten Rembang. DKP. Rembang.

Fitri, A.D.P; Boesono, H; Sabdono, A; Nadiaadlina, N. 2017. Resources Management Startegy for Mud Crab (Scylla spp.) in Pemalang Regency. IOP Conf. Series: Earth and Environemental Science. 55012008

Fitri, A.D.P; Boesono, H; Sabdono, A; Supadminingsih, F.N; Nadiaadlina, N. 2017. The Mud Crab (Scylla serrata) 
Behavior in Different Inclination Angles of Funnel and Escape Vent for Trep Net. AACL Bioflux 10 (2): 191199

Kurniadi. 2010. Kecamatan Rembang dalam Angka Tahun 2010. Badan Pusat Statistik. Rembang

Mahmudi, H. 2012. Analisis Hasil Tangkapan Fyke Net dengan Perbedaan Sudut Kemiringan Penaju di Perairan Pati, Jawa Tengah. [skripsi]. Tidak Dipublikasikan. Fakultas Perikanan dan Ilmu Kelautan. Universitas Diponegoro
Martasuganda, S. 2005. Set Net (Teichi ami). Departemen Pemanfataan Sumberdaya Perikanan Fakultas Perikanan dan Ilmu Kelautan Institut Pertanian Bogor. Bogor.

Monintja, D. 2001. Pemanfaatan Pesisir dan Laut untuk Kegiatan Perikanan Tangkap. Prosiding. Pelatihan Untuk Pelatih Pengelolaan Wilayah Pesisir Terpadu. Bogor:PK.SPL-Institut Pertanian Bogor. 45-47.

\section{Lampiran 1. Konstruksi Bubu Bercelh Pelolosan}

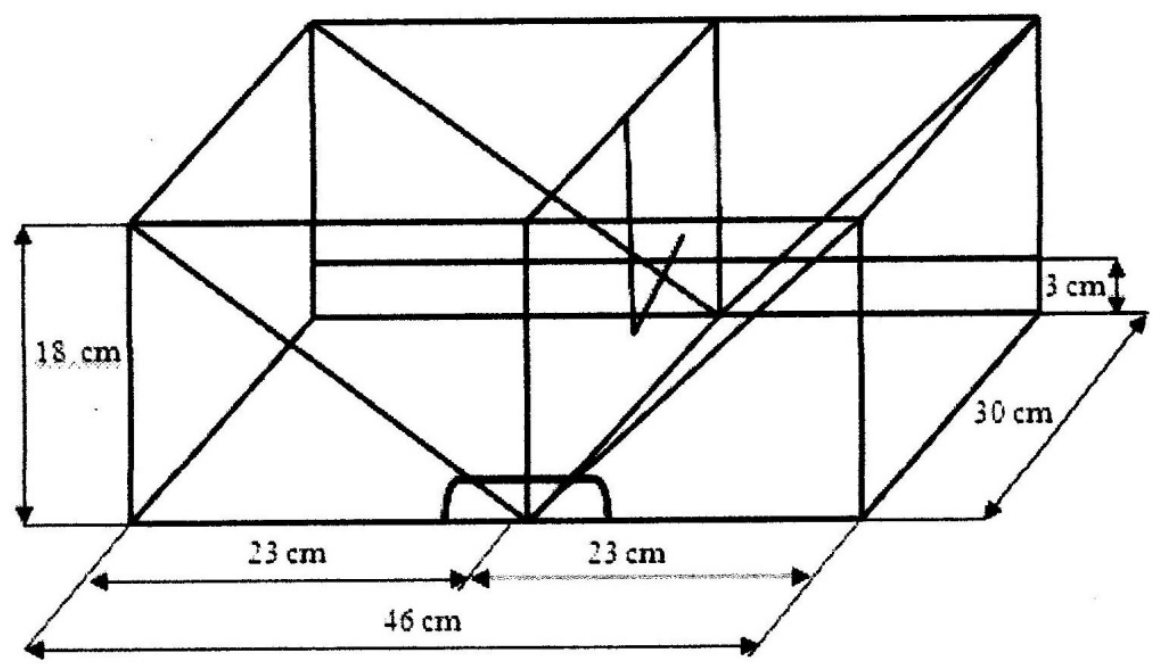

Spesifikasi rancang bangun alat tangkap bubu bercelah pelolosan, adalah sebagai berikut :
1. Dimensi ( $\mathrm{p} \times 1 \times \mathrm{t})$
2. Mesh size
3. Celah pelolosan (tinggi)
4. Bahan
- Rangka
- Badan jaring
- Celah pelolosan
: $46 \times 30 \times 18 \mathrm{~cm}$

$$
\text { : } 2,55 \mathrm{~cm}
$$$$
\text { : } 3 \mathrm{~cm}
$$

: $\operatorname{Besi}(\varnothing 0,36 \mathrm{~cm})$

: Besi (Ø 0,36 cm)

5. Ijeb/mulut bubu
- Panjang
: $9 \mathrm{~cm}$
- Lebar 
Lampiran 2. Desain bubu bercelah pelolosan

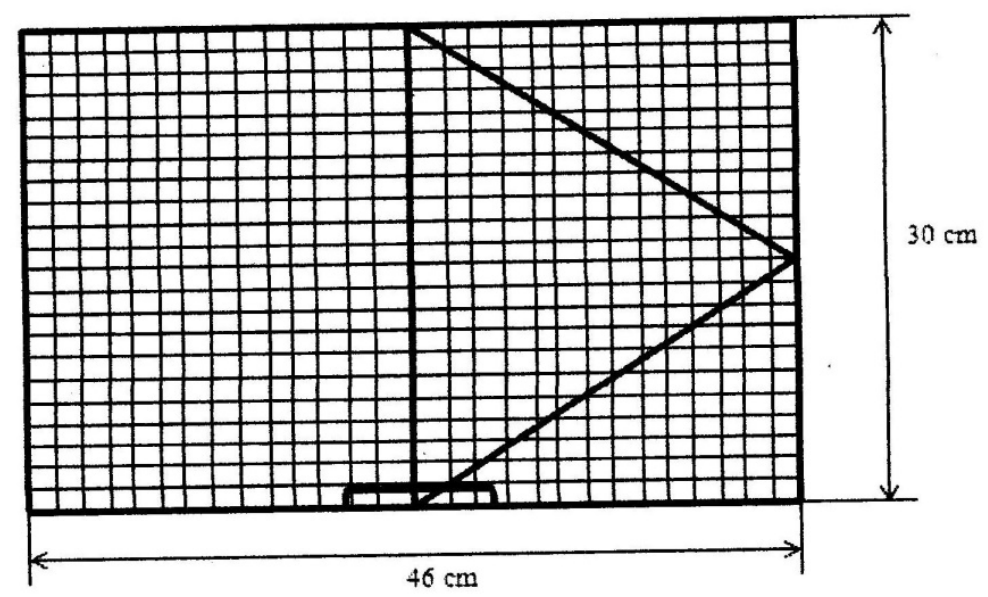

Tampak Atas

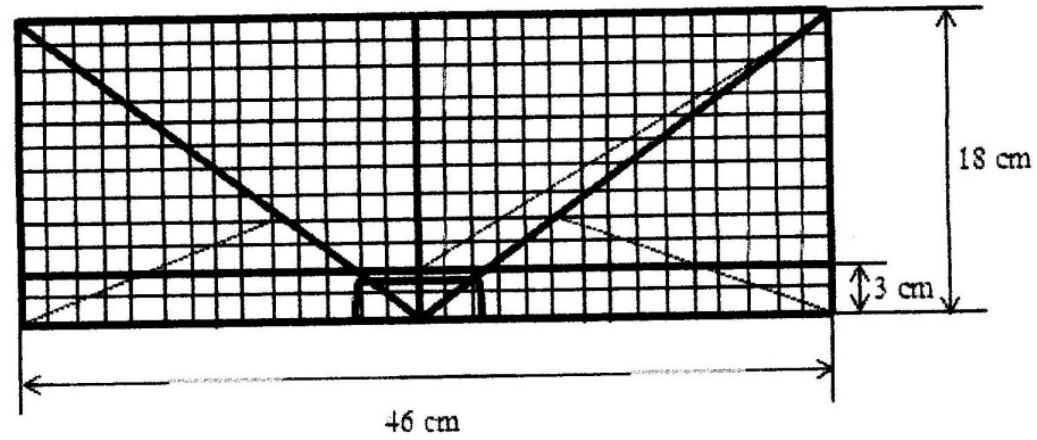

Tampak Samping

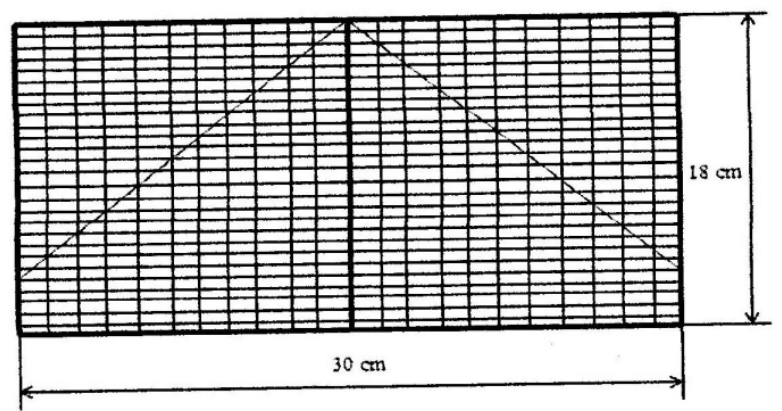

Tampak Depan

${ }^{\circ}$ Copyright by Saintek Perikanan (Indonesian Journal of Fisheries Science and Technology), ISSN : 1858-4748 